\title{
Pro and Con of Single Subject Research in Adapted Physical Education and the Guidance for an Appropriate Research Designing
}

\author{
Kihong Kim ${ }^{*}$ \\ Yongin University, Yongin, Korea
}

Received: December 5, 2018

Accepted: January 20, 2018

Published online: January 31, 2018

Keywords:

$A B$ design

ABAB design

Baseline

Intervention

Multiple Baseline design

Single subject research design
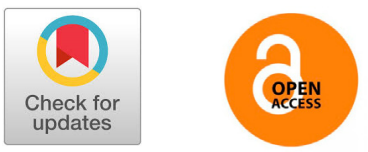

\begin{abstract}
PURPOSE The purpose of this study was to describe pro and con related to the single subject research method in adapted physical education and to provide the guideline for checking the appropriateness by the checklist before setting the single subject design.

METHODS The research review based on using the single subject research method was applied in this study. The effectiveness of intervention for the single subject with disability could be appropriately interpreted based on the differences of disability level after adapted physical activity instruction. However, the variable threats to the experimental design and the cautions might be needed to avoid those traps of mistakes before setting up the single subject research design in the adapted physical educational instruction, therefore, the advantages and limitations at each single subject design were subscribed.

RESULTS The checklist of experimental setting were provided to minimize the threats of internal and external validity such as history, maturation, testing, or measurement error.

CONCLUSIONS The author of this article summarized the items to be checked for single subject research design based on the review of many studies done by Glass et al. (1975), Tawney and Gast (1984), Logan, Hickman, Harris, and Heriza (2008), Dixon et al. (2012), Byiers et al. (2012), and Haegele and Godge. (2015). It could help the researcher to conceptualize the reality of experimental setting and to reduce the misunderstanding and error in designing of single subject research prior to activating the experiment.
\end{abstract}

(c) The Asian Society of Kinesiology and Korean Academy of Kinesiology

\section{Introduction}

Single subject research design is one of the effective research methods in adapted physical education. There were many faculty and students who were interested about adapted physical activities and its effectiveness such as physical as well as mental improvements by the activities on the students with disabilities. To investigate the effects, the single subject research method was recommended for the researchers to identify the behavioral changes of people with disabilities (Haegele

\footnotetext{
*Correspondence: Kihong Kim, Yongin University, 134 Cheoin-gu, Yongin, Gyeonggi-do, Korea.

E-mail adress: jamnikim@hanmail.net
}

\& Godge, 2015). Originally, Single subject designs could be traced back to the earlier period of applied behavior analysis (Dixon, Vogel, \& Tarbox, 2012). Single subject research is not based on the statistical analysis such as correlational or descriptive methods but an experimental method compared by document causal relationships between independent and dependent variables to control the threats on the validity and reliability of the research (Martella, Nelson, \& Marchand-Martella, 1999). Since Sidman (1960) operated the single subject design methodology first and proved the behavioral practices at different levels of the target learners in the educational settings. The target population with disabilities in the special education field were benefited by the research method to

(7) This is an open-access article distributed under the terms of the Creative Commons Attribution License (http://creativecommons.org/licenses/by-nc/4.0/), which permits unrestricted use, distribution, and reproduction in any medium, provided the original work is properly cited. 
identify the relevance of their behavior characteristics. (Dunlap \& Kern, 1997). Researchers in adapted physical education also concerned about identifying the effects of instructional treatments on the achievements of motor skills. However, the problems such as level differences by each individual disability type, performance, and behavioral practice made the research design difficult to generalize. The problems were seeded same as to the psychological research specially applied behavioral area and have met the single subject designs in which the internal and external validity as well as reliability could be threatened at minimum by causal related interpretation among the changes of an individual's behavior (Birnbrauer, Peterson, \& Solnick, 1974; Kratochwill, 1978). Because the evaluation of intervention effects for people with clinical conditions usually relied on individual effects, rather than group effects, a single-subject design would be necessary in adapted physical education research. (Baker \& McLeod, 2011). In the review of article of Lee \& Haegele (2015), the characteristics of heterogeneity of participants make single subject design more suitable to demonstrate the internal validity and experimental control comparing to the group experimental design (Byiers, Reichle, \& Symons, 2012).

\section{Pro and Con of Single Subject Research Design}

\section{AB Simple Time Series Design}

$\mathrm{AB}$ single subject design is setting on the baseline logic under two experimental conditions, $\mathrm{A}$ as baseline and $\mathrm{B}$ as intervention, which commonly referred as reversal design and also called as a simple repeated time series by Glass, Wilson, \& Gottman (1975). The baseline (A) phase is as usual condition same to the group designs in which no intervention is provided and then compared to the intervention (B) phase with the pattern of the performance of the target subject.

Pro The design can be applied to the clinical investigations and available to identify the rare phenomena such as the stereotyped behavioral changes of people with autistic spectrum disorder. The new technical skills could be developed and the results can provide the refinement of the techniques (Lazarus \& Davison, 1971).
Con It is only possible to isolate the dependent and independent variable with the measurement target behavior under both $\mathrm{A}$ and $\mathrm{B}$ and very dependent on the behavioral changes. If no apparent outcomes would be shown, the researcher is only available to report on the level or the trend of the data based on the broadly defined condition. Many threats to internal and external validity such as history, maturation, or other experimental disruption effects can provide limitations of the research (Kratochwill, 1978).

\section{ABAB Repeated Time Series Design}

This design was called as reversal design, withdrawal design, operant design, and equivalent time series design (Campbell \& Stanley, 1966; Glass, Willson, \& Gottman, 1975; Leitenberg, 1973). The process of experiment using this design is consisted by the repeated phases of baseline, intervention, and withdrawal of intervention.

Pro The advantages of this design are to demonstrate the relationship between dependent and independent variables where a strategy by a reinforcement is used to handle the frequency of the target subject's behavioral changes (Schleien, Kiernan, \& Wehman, 1981). The most powerful exhibition of causality could be demonstrated. Many types of time series could be applied by baseline and intervention combination such as $\mathrm{ABA}, \mathrm{BABA}$ and multi-treatment designs like $\mathrm{ABABCBC}$ in $\mathrm{A}$ as a baseline without intervention, $\mathrm{B}$ as an intervention, $\mathrm{C}$ as a different intervention in the research period. To control the internal validity threats such as history and maturation, this design could be used by setting up the baseline, intervention, and withdrawal of intervention followed by each condition in the repeated phases (Kratochwill, 1978).

Con The ethical concerns are main limitations in this design. Even though the withdrawal is brief for the intervention effectiveness, it is unethical during the durable behavior changes. In the case of checking the target behavior harmful to the subject or other students, counting such frequence is against the ethical concerns. The inability to care the variables not reversible is main disadvantage and order effect of intervention prohibit to interpret appropriately experimental pursue (Todd, 1996). 


\section{Multiple Baseline Design}

The pioneer researchers who were using this design were Baer, Wolf, \& Risley (1968). The researcher can use this design to test the effects of an intervention toward different behavior patterns, settings, or target population more than one. Therefore, it is available to treat a number of motor performance at same time during the experiment (Birnbrauer, Peterson, \& Solnick, 1974). Many researchers are utilizing this design by replication of the intervention across subjects (Donder \& Nietupski, 1981)

Pro The advantage of this design is to control the threats to internal validity such as history (Kazdin \& Kopel, 1975). The one of characteristics of intervention in this design is related to the non-withdrawal of intervention required. The convenience in conceptualizing and implementing is another advantage for the teacher or parents who are conducting research (Murphey \& Bryan, 1980). Therefore, many demands in the applied setting such as academic skill which is not irreversible could be handle by this design instead of ABAB design (Baer, Wolf, \& Risley, 1968).

Con The problems in this design were existed by the baseline conditions which should be concurrently measured with multiple baselines. Also, prolonged baseline period can be problematic due to the practical effects. Those limitations make the researcher hard to decide the adequate baseline trials and consume time and expenses in the experimental setting (Scott \& Goetz, 1980).

\section{Checklist for Single Subject Research Design}

The author of this article summarized the items to be checked before setting single subject research design based on the review of many papers done by Glass, Willson, \& Gottman (1975), Tawney \& Gast (1984), Logan et al. (2008), Dixon, Boge, \& Tarbox (2012), Byiers, Reichle, \& Symons (2012), and Haegele \& Godge (2015). The following items are created to conceptualize the reality of experimental setting and to reduce the misunderstanding and error in designing of single subject research prior to activating the experiment.
- Is there any similarity in the target behavior when two subjects were placed?

- Is the level of age almost same to each other when two subjects were placed?

- Is direct observation utilized to identify the target subject's character?

- Is test instrument used to identify the target subject's character?

- Is there any relationship between target behavior and the notice of subject's character?

- Is there any standard to recruit subject?

-Is there any logical basis to recruit the subject?

- Is a definition of target behavior set in detail and operative?

-If the target behavior is related to the behavior problem, is functional test ready before the baseline trial?

- Is the description provided about advantage as well as resource added to the behavior problem of the target subject with disability or typical clinical condition?

- Is the intervention selected through behavior problem understanding?

-Is there comment related to the report sheet?

- Is the right reaction and wrong reaction defined in detail?

-If there is the score to be earned, is the gap within scores appropriately distributed?

- Are the record method and procedure described properly?

- Has the reliability been secured between observers?

- Is there comment related to 2 nd or $3 r d$ observer?

- Is the observer trained?

- Is there a standard to end of observation?

-Is the in-service training provided for the observer?

- Is there any notice when the reliability was secured?

- Is there a formula for the reliability calculation?

- Is the intervention described in detail to repeat?

-Is there comments about intervenor?

- Is the experimental setting familiar to the researcher?

- Is the environment of experimental setting described in detail?

- Is the social circumstance of experimental setting described in detail?

- Is the reason to choose test instrument was described in 
detail?

- Is there the procedure to select test instrument prior to the experiment?

- Is the faithfulness considered?

- Is there a formula to calculate the faithfulness?

- Is there a training plan for the intervenor to increase the faithfulness?

- Is there any description related to the social validity of the faithfulness?

- Is the experiment design explained?

- Is there an agreement between noted experimental design and real design?

- Is the reason explained why the experiment design is selected?

- Is the total period of experiment noticed?

- Is the explanation related to the condition and difference of baseline and intervention?

- Is the time of switching intervention from the baseline appropriate?

- If the training period set separately, is the reason described?

- Is the reason to end of intervention described?

- In the case of multiple baseline design, is the standard of intervention to different situation or target behavior described in detail?

- Is the explanation related to the intervention and withdrawal described with its difference?

\section{Conclusions}

In conclusion, the checklist could be used to prepare the single-subject research design and able to reduce the possible mistakes such as the weakness of data interpretation, internal and external validity, or reliability which could be happened by the vulnerable research structure. The checklist could be a method to preview the circumstances overall the research prior to beginning of the single subject research design, and the quality of data collection might be secured.

\section{Conflicts of Interest}

The authors declare no conflict of interest.

\section{References}

Baer, D. M., Wolf, M. M., \& Risley, T. R. (1968). Some Current Dimensions of Applied Behavior Analysis. Journal of Applied Behavior Analysis, 1(1), 91-97.

Baker, E., \& McLeod, S. (2011). Evidence-based Practice for Children with Speech Sound Disorders: Part I Narrative Review, Language, Speech, and Hearing Services in Schools, 42, 102-139.

Birnbrauer, J., Peterson, C., \& Solnick, J. (1974). Designing and Interpretation of Studies of Single Subjects. American Journal of Mental Deficiency, 79, 191-203.

Byiers, B. J., Reichle, J., \& Symons, F. J. (2012). Single-subject Experimental Design for Evidence-based Practice. American Jounal of Speech-Language Pathology, 21(4), 397-414.

Campbell, D. T., \& Stanley, J. C. (1966). Experimental and Quasiexperimental Designs for Research. Chicago: Rand McNally.

Dixon, D., Boge, T., \& Tarbox, J. (2012). A Brief History of Functional Analysis and Applied Behavior Analysis. In Matson, J.L. (Ed.) Functional Assessment for Challenging Behaviors, Autism and Child Psychopathology Series, Springer Science+Business Media, LLC 2012.

Donder, D., \& Nietupski, J. (1981). Nonhandicapped Adolescents Teaching Playground Skills to Their Mentally Retarded Peers: Toward a Less Restrictive Middle School Environment. Education and Training of the Mentally Retarded, 16, 270-276.

Dunlap, G., \& Kern, K., (1997). The Relevance of Behavior Analysis to Special Education. In J.L., Paul, M. Churron, H. Roselli-Kostoryz, W. Morse, K. Marfo, C. Lavely, \& D. Thomas (Eds.), Foundations of Special Education: Basic Knowledge Informing Research and Practice in Special Education (pp. 279-290). Pacific Grove, CA:Brooks/Cole.

Glass, G. V., Willson, V. L., \& Gottman, J. M. (1975). Design and Analysis of Time-series Experiment of Mentally Retarded Children. (Cooperative Research Project No. 619) Cooperative Research Program of the Office of Education, U.S. Department of Health, Education and Welfare.

Haegele, J. A., \& Godge, S. (2015). The Applied Behavior Analysis 
Research Paradigm and Single-Subject Designs in Adapted Physical Activity Research. Adapted Physical Activity Quarterly, 32(4), 285-301.

Kazdin, A. E.l \& Kopel, S. A. (1975). On resolving Ambiguities of the Multiple-baseline Design: Problems and Recommendations. Behavior Therapy, 6, 601-608.

Kratochwill, T. R. (1978). Foundations of Time-Series Research. In T. R. Kratochiwill (Ed.), Single Subject Research: Strategies for Evaluating Change (pp. 2-100). New York: Academic Press.

Lazarus, A. A., \& Davison, G. C. (1971). Clinical Innovation in Research and Practice. In A. E. Bergin \& S. I. Garfield (Eds.), Handbook of Psychotherapy and Behavior Change: An Empirical Analysis. New York: Wiley.

Lee, J., \& Haegele, J. A. (2015). A Cross-disciplinary Comparison of Published Articles: Adapted Physical Activity and Special Education. European Journal of Adapted Physical Activity, 8(1), 7-20.

Leitenberg, H. (1973). The Use of Single-case Methodology in Psychotherapy. Research. Journal of Abnormal Psychology, 82(1), 87-101.

Logan, L. R., Hickman, R. B., Harris, S. R., \& Heriza, C. B. (2008). Single-subject Research Design: Recommendations for Level of Evidence and Quality Rating. Developmental Medicine \& Child Neurology, 50, 99-103.
Martella, R., Nelson, J., \& Marchand-Martella, N. (1999). Research Methods: Learning to Become a Critical Research Consumer. Boston: Allyn \& Bacon.

Murphy, R. J., \& Bryan, A. J. (1980). Multiple-baseline and Multiple-probe Designs: Practical Alternatives for Special Education Assessment and Evaluation. The Journal of Special Education, 4(3), 325-335.

Schleien, S. J., Wehman, P., \& Kiernan, J. (1981). Teaching Leisure Skills to Severly Handicapped Adults: An Age-appropriate Dart Game. Journal of Applied Behavior Analysis, 14, 513519.

Scott, L., \& Goetz, E. (1980). Issues in the Collection of In-class Data by Teachers. Education and Treatment of Children, 3(1), 6571.

Sidman, M. (1960). Tactics of Scientific Research: Evaluating Experimental Data in Psychology. New York: Basic Books.

Tawney, J. W., \& Gast, D. L. (1984). Single Subject Research in Special Education. Columbus OH: Charles E. Merrill Publishing Company.

Todd, J. T. (1996). Division 25: Experimental Analysis of Behavior. In D. A. Dewsbury (Ed.), Unification Through Division: Histories of the Divisions of the American Psychological Association. Washington, DC: APA Books. 